\title{
Haemodynamic effects of paroxysmal supraventricular tachycardia in an endurance athlete during exercise testing
}

\author{
Paul Zimmermann, ${ }^{1}$ Christoph Lutter ${ }^{2}$
}

${ }^{1}$ Cardiology, Sozialstiftung Bamberg, Bamberg, Germany ${ }^{2}$ Department of Orthopedics, University Medical Center, Rostock, Germany

Correspondence to Dr Christoph Lutter: christoph.lutter@googlemail. com

Accepted 10 October 2019

\section{DESCRIPTION}

Atrial fibrillation (AF) is a commonly known heart rhythm abnormality which occurs in the general population as well as in endurance athletes. Various studies have provided evidence of increased prevalence of this condition in such athletes compared to the general population; various potential trigger mechanisms have been discussed previously. ${ }^{12}$ We present the case of a 60-year-old male endurance athlete who participated in several triathlons of 'ironman distance' during his sports career. He was $188 \mathrm{~cm}$ tall, weighed $92 \mathrm{~kg}$ (body mass index (BMI) 26) and his training level averaged 10-15 hours/week (swimming, cycling and running). The 60 -year-old patient presented in our department with unknown symptoms, including intermittent shortness of breath during his training sessions and heart palpitations. His medical history showed an isthmus ablation caused by typical atrial flutter and a clinically stable arterial hypertension. The echocardiographic data showed a normal size of the left ventricle $(42 \mathrm{~mm})$, no hypertrophia of the left ventricular walls (IVSd $11 \mathrm{~mm}$, PWTs $11 \mathrm{~mm}$ ), minimal enlargement of the left atrium (LA $21 \mathrm{qcm}$ ) and a normal ejection fraction (55\%).

In order to examine the patient more extensively, we decided to perform a cardiopulmonary exercise testing (CPEX) on an ergometer bike. During the test, the patient developed an episode of paroxysmal supraventricular tachycardia (SVT, maximum

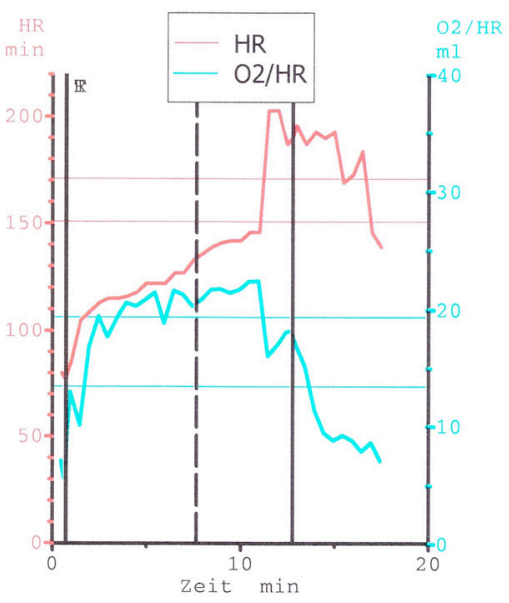

Figure 1 Impairment of the oxygen pulse during the CPEX caused by atrial fibrillation (starting within minute 11) and showing the gap between the tachycardia (red) and oxygen pulse (blue). CPEX, cardiopulmonary exercise testing.

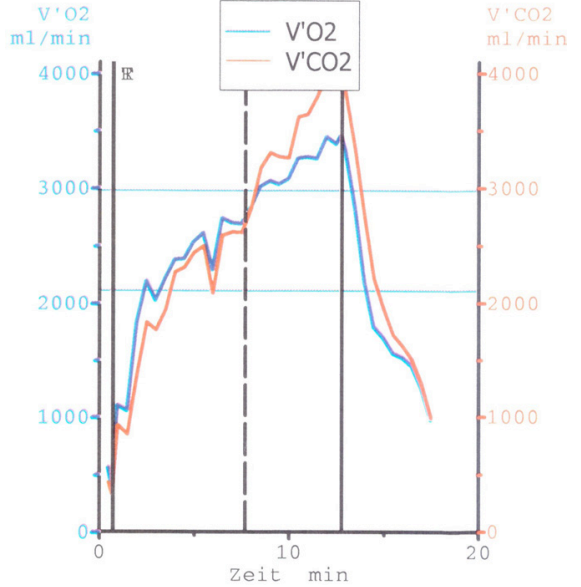

Figure 2 Graphical record of the athlete's impairment referring his maximum $\mathrm{VO}_{2}$ uptake caused by atrial fibrillation, Missing the typical levelling off phenomenon by endurance athletes at the end of the CPEX testing. CPEX, cardiopulmonary exercise testing.

effort $250 \mathrm{~W})$. We were able to graphically record the degree of impairment of the athlete's performance (figures 1 and 2). The patient's oxygen pulse decreased pathologically and his $\mathrm{VO}_{2}$ oxygen uptake during the SVT was limited (figures 1 and 2). After he completed ergometer testing, the patient recovered very fast and his heart rhythm returned to a stable sinus rhythm, similar to pretesting conditions. Our case graphically shows the haemodynamic influence and reduced performance of a patient with a paroxysmal AF during CPEX and therefore highlights the importance of a stable sinus rhythm for optimal performance in endurance athletes. Various aspects including the pathological mechanisms and the relation between high endurance training and the prevalence of AF are widely discussed. Changes in the left atrial substrate, that is, an increased size of the LA and histological fibrosis, might also play an important role. Additionally, the amplitude of the autonomic nervous system may increase the risk of developing AF in intensive endurance athletes. ${ }^{13}$ These presumptions can be confirmed by an animal model in rats in which chronic endurance exercise increased the AF susceptibility with atrial dilatation, autonomic changes and fibrosis. Even augmented baroreflex responsiveness and increased cardiomyocyte sensitivity to cholinergic stimulation are presumed to cause higher prevalence of AF. ${ }^{4}$ Monitoring the training of of endurance athletes' shows some evidence that an accumulation of lifetime 
training hours and participation in competitions substantially increases the risk of AF in aging endurance athletes. ${ }^{5}$ The risk of $\mathrm{AF}$ in young competitive athletes is estimated to be low $^{5}$ due to a U-shaped dose dependency in relation to the athlete's activity. ${ }^{1}$ The development of AF in our endurance athletes collective with performed ablation of atrial flutter is a commonly observed occurrence. ${ }^{6}$ In long-term follow-up, paroxysmal AF remained stable in half of the athletes, only developing into permanent $\mathrm{AF}$ in a minority of this population. ${ }^{3}$ The previously mentioned strenuous endurance exercise (SEE) related AF or paroxysmal AF in young and middle-aged athletes syndrome $\mathrm{e}^{7}$ is quite a common finding in (young) endurance athletes, and even our athlete/ patient could fulfil its criteria. A relatively common finding in highly trained endurance athletes is an atrial cardiomyopathy which is characterised by right and left atria enlargement and fibrosis (often detected in an MRI).

\section{Learning points}

- The presented case graphically shows an impressing haemodynamic influence of heart rhythm abnormality on the athlete's performance during a cardiopulmonary exercise testing.

- While different pathological mechanisms for underlying etiological reasons are discussed, maximum effort should be exerted to establish a stable sinus rhythm in endurance athletes.

- Therapeutic approaches should be individually tailored according to the athletes' demands.
Finally, although some evidence regarding atrial anatomic adaptations was reported by Müssigbrodt $e t \mathrm{al}^{1}$ and by Fragakis et $a l^{8}$, alterations in autonomic nervous system, chronic systematic inflammation and fibrosis have been proposed as potential mechanisms for paroxysmal SVT induced by endurance exercise. ${ }^{258}$ However, this hypothesis is speculative.

Contributors Both authors wrote the manuscript and gave final approval.

Funding The authors have not declared a specific grant for this research from any funding agency in the public, commercial or not-for-profit sectors.

Competing interests None declared.

Patient consent for publication Obtained.

Provenance and peer review Not commissioned; externally peer reviewed.

\section{REFERENCES}

1 Müssigbrodt A, Richter S, Hindricks G, et al. Vorhofflimmern bei Ausdauersportlern (atrial fibrillation in endurance athletes); Deutsche Zeitschrift für Sportmedizin, Jahrgang 61, NR. 92010.

2 Calvo N, Brugada J, Sitges M, et al. Atrial fibrillation and atrial flutter in athletes. Br J Sports Med 2012;46 Suppl 1:i37-43.

3 Hoogsteen J, Schep G, Van Hemel NM, et al. Paroxysmal atrial fibrillation in male endurance athletes. A 9-year follow up. Europace 2004;6:222-8.

4 Guasch E, Benito B, Qi X, et al. Atrial fibrillation promotion by endurance exercise: demonstration and mechanistic exploration in an animal model. J Am Coll Cardiol 2013;62:68-77.

5 Wilhelm M. Atrial fibrillation in endurance athletes. Eur J Prev Cardiol 2014;21:1040-8.

6 Heidbüchel $H$, Anné W, Willems R, et al. Endurance sports is a risk factor for atrial fibrillation after ablation for atrial flutter. Int J Cardiol 2006;107:67-72.

7 Sanchis-Gomar F, Perez-Quilis C, Lippi G, et al. Atrial fibrillation in highly trained endurance athletes - description of a syndrome. Int J Cardiol 2017;226:11-20.

8 Fragakis N, Vicedomini G, Pappone C, et al. Endurance sport activity and risk of atrial fibrillation - epidemiology, proposed mechanisms and management. Arrhythm Electrophysiol Rev 2014;3:15-19.

Copyright 2019 BMJ Publishing Group. All rights reserved. For permission to reuse any of this content visit

https://www.bmj.com/company/products-services/rights-and-licensing/permissions/

BMJ Case Report Fellows may re-use this article for personal use and teaching without any further permission.

Become a Fellow of BMJ Case Reports today and you can:

- Submit as many cases as you like

- Enjoy fast sympathetic peer review and rapid publication of accepted articles

- Access all the published articles

- Re-use any of the published material for personal use and teaching without further permission

Customer Service

If you have any further queries about your subscription, please contact our customer services team on +44 (0) 2071111105 or via email at support@bmj.com.

Visit casereports.bmj.com for more articles like this and to become a Fellow 